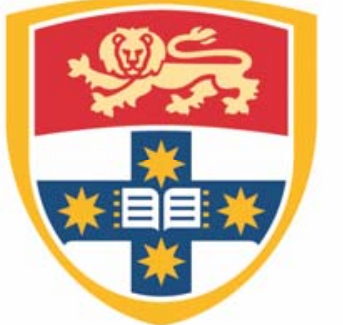

THE UNIVERSITY OF

SYDNEY

Economics Working Paper Series

$2015-23$

The Value of a Healthy Home:

Lead Paint Remediation and Housing Values

Stephen B. Billings \& Kevin Schnepel

December 2015 


\title{
The Value of a Healthy Home: Lead Paint Remediation and Housing Values
}

\author{
Stephen B. Billings* $\quad$ Kevin T. Schnepel ${ }^{\dagger}$
}

\begin{abstract}
The presence of lead paint significantly impairs cognitive and behavioral development, yet little is known about how this residencespecific environmental health risk affects property values. In this paper, we estimate the benefits of lead-paint remediation on housing prices. Using data on all homes that applied to a HUD-funded program in Charlotte, North Carolina, we adopt a difference-indifferences estimator that compares values among remediated properties with those for which an inspection does not identify a lead paint hazard. Results indicate that remediation has large benefits-a typical investment of $\$ 7,291$ is associated with a capitalized benefit of $\$ 20,323$ as well as a reduction in residential turnover.
\end{abstract}

Keywords: lead exposure, lead paint, lead hazard control, environmental quality, urban environmental health, difference-in-differences

JEL classification codes: Q51, Q52, Q58, R21, R23, R31, I18

\footnotetext{
*stephen.billings@uncc.edu, Department of Economics, University of North Carolina Charlotte

${ }^{\dagger}$ kevin.schnepel@sydney.edu.au, School of Economics, The University of Sydney

Acknowledgements: We thank Anna Aizer, Paul Gaggl, Ludovica Gazze, Scott Holladay, Jessica Wolpaw Reyes, Heather Royer for helpful comments/discussions as well as conversations with participants at the 2015 NBER Summer Institute and 2015 Southern Economic
} 


\section{Introduction}

Residents of disadvantaged neighborhoods typically face an elevated risk of exposure to harmful environmental toxins due to an increased prevalence of key sources of pollution such as dilapidated homes, industrial activity and busy roads. Beyond industrial pollutants, the most pervasive source of toxins is lead paint in older residential structures. ${ }^{2}$ Recent work by Aizer et al. (2015), Zhang et al. (2013), and Miranda et al. (2007), find detrimental effects of childhood exposure to lead paint hazards on a number of education outcomes. ${ }^{3}$ Beyond the effects of lead pollution on child health and development, the presence of lead impacts neighborhoods through its capitalization in housing values and the sorting of residents to/away from homes with lead paint. As a result, the presence of lead is likely an important mechanism contributing to the profound relationship between neighborhood of birth and later economic wellbeing (Chetty et al., 2015; Chetty and Hendren, 2015; Chetty et al., 2014).

A growing set of papers in environmental economics use hedonic methods to estimate the capitalization of environmental disamenitites into housing prices. Exposure to toxins through poor air quality (Chay and Greenstone, 2005), EPA Superfund sites (Gamper-Rabindran and Timmins, 2013; Greenstone and Gallagher, 2008), Toxic Release Inventory (TRI) facilities (Currie et al., 2015; Mastromonaco, 2015; Sanders, 2012), and other polluted areas (Davis, 2004; Leggett and Bockstael, 2000) are associated with lower housing values. Due to the endogenous sorting of lower income families toward affordable neighborhoods with higher health risks (Banzhaf and Walsh, 2008; Kahn, 2000), research that estimates the housing-price capitalization of environmental disamenities typically adopts quasi-experimental research designs based on information shocks or discontinuities in selection criteria for environmental cleanup.

This paper contributes to this literature by providing estimates of the value of

Association. We would also like to thank Tena Ward and Ed Norman from the North Carolina Childhood Lead Poisoning Prevention Program; Andy Baxter from Charlotte-Mecklenburg Schools; David Jacobs of National Center for Healthy Housing and Diana Adams of LeadSafe Charlotte.

${ }^{2}$ The National Survey of Lead and Allergens in Housing estimated that 38 million housing units in the United States (40 percent of all housing units) contained lead paint and approximately 24 million had significant lead paint hazards (Jacobs et al., 2002).

${ }^{3}$ See EPA (2013) for a comprehensive review of the vast literature documenting the effects of lead exposure on cognitive and behavioral outcomes. 
residential lead exposure risk and the benefits of lead remediation programs. Since the primary source of this health risk is limited to specific structures, we are able to compare the estimated capitalized benefits directly with the actual costs of remediation. The remediation program we evaluate is the most common way in which the federal government addresses lead hazards in homes across the United States. Since 1998, the U.S. Department of Housing and Urban Development (HUD) has provided more than $\$ 1.2$ billion in grants through its Lead Hazard Control Program to target exposure risk in homes occupied by lower income residents. ${ }^{4}$ We focus on one of these HUD-funded programs, LeadSafe Charlotte, which remediated over 2,000 parcels between 1998 and 2014 in Charlotte, North Carolina.

We combine administrative data from LeadSafe Charlotte with county assessor parcel records and use a difference-in-difference research design to evaluate the effect of lead paint hazard remediation on property values. In order to construct a relevant control group of non-lead remediated homes, we exploit the fact that approximately $30 \%$ of applicants to LeadSafe Charlotte believed they were at risk for lead paint but were found to be safe from lead after the LeadSafe inspection. ${ }^{5}$ Among the LeadSafe applicants, we are able to incorporate 960 parcels with lead remediation and 400 parcels with no remediation into our difference-in-difference estimates. ${ }^{6}$ Remediated and non-remediated parcels have similar housing price trends prior to the lead inspection date and even satisfy the stricter criteria of being balanced on observable housing attributes conditional on neighborhood fixed effects.

Similar to recent studies focusing on salient exposure shocks through the Environmental Protection Agency's (EPA) Toxic Release Inventory (TRI) program (Currie et al., 2015; Mastromonaco, 2015; Sanders, 2012), we exploit a lead exposure shock which provides salient information about residence-specific lead paint hazards to current and potential homeowners. In this setting, information

\footnotetext{
${ }^{4}$ Totals allocated to the Lead Hazard Control Program were drawn from annual funding announcements available from https://www.federalregister.gov [accessed 6 November 2015].

${ }^{5}$ Home owners may have applied due to previous elevated blood lead tests at their home or due to the belief that existing paint contained lead. In both cases, control group parcels were found to have paint that did not contain lead or had lead based paint that was not at risk to transfer lead to residents and thus labelled "safe from lead".

${ }^{6}$ We focus on single-residence parcels due to the limited number of multi-family parcels sold during this time period as well as the fact that lead remediation often occurred for a subset of units within an apartment complex.
} 
relevant to remediated homes varies substantially from that of non-remediated homes due to a highly visible lead remediation process. Due to the toxic nature of lead, remediation requires signage around the outside of the home about the presence of lead, plastic sealing of the house, and workers with protective suits and respirators. Homebuyers of non-remediated properties often do not learn about prior lead inspections until the home is under contract for purchase, and also may be concerned about exposure and future remediation costs due to the natural deterioration of painted surfaces. ${ }^{7}$

We find a large and statistically significant effect of lead remediation on housing values. The capitalized benefits of lead remediation are $\$ 20,323$, or $25 \%$, of the average sales price in our LeadSafe applicant sample. Based on the average cost of lead remediation in our dataset, $\$ 7,291$, we estimate a net benefit of $\$ 13,032$ per home or a return on investment of $179 \% .^{8}$ The large net benefits of lead remediation are consistent with prior environmental risk research which documents a larger decline in sales price than the capitalized value of insurance premiums for properties located within a flood zone after major storms (Bin and Landry, 2013; MacDonald et al., 1987). In our case, the presence of lead paint generates uncertainty in both the risk of exposure as well as the costs of remediation. Several falsification tests and robustness checks confirm our effects and identification assumptions-including one in which we estimate no effects for nearest-parcel neighbors of treatment and control properties. We further show that our estimates are unlikely to be due to other property improvements that coincide with lead remediation or follow lead remediation. Finally, we find that homeowners are less likely to sell their homes after lead remediation, consistent with a story of decreased neighborhood turnover after the removal of lead.

Overall, our estimates imply that the presence of lead pollution significantly depresses housing prices in neighborhoods with older housing stock. The contribution of this pollutant to housing value is similar to recent estimates of the effects of an opening of a large toxic industrial plant within one mile of a residen-

${ }^{7}$ Lead paint disclosure laws dictate the disclosure of prior lead paint inspections at the time a home is under contract for purchase and allow potential homebuyers to conduct further inspections or request lead remediation as a condition of sale.

${ }^{8}$ Our costs of remediation do not include the costs of inspection, which average about $\$ 650$ for the LeadSafe program. 
tial property-Currie et al. (2015) and Mastromonaco (2015) find a decrease of $11 \%$ (approximately $\$ 15,000$ to $\$ 40,000$ ) following the opening of a TRI facility. The fact that the magnitude of our estimates is similar to that of changes in toxic exposure from polluting plants may simply reflect different underlying forces which generate sizeable valuations: the presence of lead paint is highly localized but can be remediated, while pollution from manufacturing plants is more dispersed but difficult to abate. Our results are also consistent with recent work by Gazze (2015) who shows that housing markets capitalize higher expected future costs for lead remediation under changes in state-level policies mandating remediation.

Recent studies find large cognitive and behavioral benefits associated with interventions following elevated blood lead levels that trigger lead paint hazard remediation (Billings and Schnepel, 2015), and from policies requiring landlords to obtain "lead-safe" certificates (Aizer et al., 2015). Our findings suggest that lead paint hazard remediation is also associated with large capitalized wealth benefits for lower-income homeowners who qualify for federally-funded programs which reduce residential exposure to the dangerous neurotoxin.

The remainder of the paper is structured as follows: Section 2 describes the LeadSafe Charlotte program and our data. Section 3 outlines our empirical strategy to identify causal effects of remediation. Section 4 presents and discusses estimated effects on property values and other outcomes. Finally, Section 5 provides some concluding remarks and further discussion of our results.

\section{LeadSafe Program and Data}

Lead was commonly used as an additive in residential paint starting in the late 19th century. Several lead paint manufacturers began to voluntarily reduce the lead content in the 1950s due to increasing public attention regarding health risks, but lead paint was not effectively banned in the United States until 1977 when the Consumer Product Safety Commission lowered the amount of allowable lead in paint to $0.06 \%$ (ATSDR, 1988). The presence of lead in paint contributes to human exposure primarily through lead dust, which is ingested by small children through hand-to-mouth activity or directly inhaled 
as particulates. ${ }^{9}$

In the early 1990s, a series of medical studies and a report by the U.S. Department of Housing and Urban Development (HUD) documented the pervasive and serious health threats of lead paint to children. HUD estimated that two-thirds of homes built before 1980 contained lead paint (Lueck, 1991). ${ }^{10}$ In response to this evidence, HUD began awarding grants to assist state and local governments with the control of lead paint hazards in lower-income, privately-owned homes. ${ }^{11}$ In 1996, Section 1018 of the Residential Lead-Based Paint Hazard Reduction Act (Title X) mandated that sellers of homes must disclose the presence of lead hazards as well as provide any prior tests for lead in the home. Disclosure of lead hazards occurs at the time a home is under contract for purchase and may not be known during the initial home search. According to Bae (2012), Title X lead disclosure laws increase the probability that a homebuyer has a property tested for lead, but does not change a homebuyer's choice of older versus newer homes in any given socioeconomic group. Funding lead remediation efforts and information disclosures represents HUD's primary strategy for combating the health threat of lead paint.

Starting in 1998, LeadSafe Charlotte began providing lead remediation under the HUD Lead-Based Paint Hazard Control (LHC) grant program. Consistent with guidelines of grant funding, remediation from LeadSafe is available to owners of a property built before 1978 who meet certain income eligibility requirements and have children under six years of age. ${ }^{12}$ Eligible property owners may apply to the LeadSafe program if they suspect that lead is present inside or outside the home. Almost all applicants are eligible since program administrators discourage individuals from applying if they do not meet eligibility criteria. After receiving an eligible applicant, LeadSafe contracts for a lead inspection of the home. In years where a home is not inspected due to limited grant funds, inspection of

${ }^{9}$ Jacobs et al. (2002), Brown et al. (2006), and Lanphear et al. (1999) provide evidence that lead dust is the primary means of lead paint exposure. Lead is also found in soil outside residences from exterior paint sources and settled particulates from air pollution prior to the phase-out of leaded gasoline.

${ }^{10}$ While lead paint is a widespread problem, the mere presence of lead paint in a home is not always a hazard and most children live safely in these homes and apartments.

${ }^{11}$ Public housing was addressed separately in 1971 through the Lead-Based Poisoning Prevention Act.

${ }^{12}$ The income eligibility requirement states that the property owner must have a household income no greater than $80 \%$ of the median income for the household size. 
the parcel is delayed to the following year.

A residential lead inspection first involves determining whether lead is present and then whether lead exposure is possible. In this context, the lead inspection labels a home as "safe from lead" or "in need of lead mitigation". Lead inspections involve systematically testing all window sills, door frames and other areas in the home with deteriorating paint or potential for lead dust. Any lead interior surface test concentration of greater than the HUD-recommended limit of 250 micrograms per square foot $\left(\mu \mathrm{g} / \mathrm{ft}^{2}\right)$ or soil area in excess of 400 micrograms per gram $(\mu \mathrm{g} / \mathrm{g})$ represents a lead hazard and generates a recommendation of remediation. Lead dust is always removed through remediation but existing lead paint may be sealed if the area does not involve moving parts (e.g. wall, ceiling). In many cases, areas with old and deteriorating paint have to be removed. The replacement of windows and doors is the most common type of remediation. For our purposes, we simplify our analysis to two distinct groups: Our treatment group consists of all homes in which the inspection triggered the need to remove lead paint hazards; Our control group includes parcels determined "safe from lead" by the LeadSafe-contracted inspector.

Approximately $70 \%$ of applicants are assigned to our treatment group and we are able to incorporate 960 treatment parcels and 400 control parcels. ${ }^{13}$ This non-trivial portion of applicants that are determined to be "safe from lead" stems from the fact that the presence of lead paint is often not obvious from visual inspection in older homes. The $30 \%$ of applicants without lead remediation represent a reasonable control group since, by completing applications, both our treatment and control groups believed their homes may contain lead paint hazards.

Since 1998, LeadSafe Charlotte has received over $\$ 17$ million dollars from HUD to reduce lead paint hazards in more than 2,000 homes within CharlotteMecklenburg County. ${ }^{14}$ The average cost of repairs among our treated parcels was $\$ 7,291$. According to data from LeadSafe Charlotte, remediation in our sample typically involved removing and replacing windows and doors; painting

\footnotetext{
${ }^{13}$ The treatment and control parcels span the time frame of data and appendix Figure 1 provides counts for treatment and control groups by LeadSafe inspection year.

${ }^{14}$ Information about the LeadSafe Charlotte program was obtained through grant reporting records from program administrators, which includes detailed records on all parcels inspected and lead remediated from 1998-2014.
} 
or installing siding on the exterior of homes; and repairing doors to avoid chipping within the door frame when opening and closing.

To estimate the effects of remediation on property values, we combine the LeadSafe Charlotte data using residential addresses with the complete assessor's records for Mecklenburg County, NC which encompasses all of Charlotte. This dataset provides information on detailed structural attributes and complete sales records from 1995 through 2014 for the full population of residential parcels in the county. We limit our analysis to single-family parcels and sales that involve arm's-length transactions. ${ }^{15}$ We augment this parcel data with building permits for all home renovations. This database allows us to incorporate information on housing stock and neighborhoods, directly accounting for some degree of home maintenance that may be correlated with lead exposure. This parcel database allows us to generate variables for prior home renovations, age, and housing structural attributes.

We also incorporate blood lead screening data from the state of North Carolina to provide another measure of lead exposure risk. North Carolina requires all children participating in Medicaid or the Special Nutrition Program for Women, Infants and Children (WIC) to be screened for lead at one or two years of age. Other children are screened if a parent responds "yes" or "don't know" to any of the questions on a Centers for Disease Control (CDC) Lead Risk Assessment Questionnaire. Approximately 25\% of children in our study area of Mecklenburg County were screened for lead in $2002 .{ }^{16}$ The blood lead surveillance data contains the following information: a child's name, birth date, test date, blood lead level (BLL), type of test, and home address. ${ }^{17}$ We use the blood lead screening data to incorporate information on the level of lead in the home prior to lead remediation, but are limited by the fact that lead test results occurred for children living in only 526 out of our 1,360 LeadSafe applicant

\footnotetext{
${ }^{15}$ As typical with most county parcel records, we cannot always identify the specific type of transaction, but we exclude transactions with excessively low prices $(<10,000)$ and missing property attributes to address this concern.

${ }^{16}$ Lead surveillance statistics by county in North Carolina is provided by the Environmental Health division of the Department of Public Health and available online at http://ehs. ncpublichealth.com/hhccehb/cehu/lead/resources.htm.

${ }^{17}$ The limit of detection for lead in blood as analyzed by the North Carolina State Laboratory is 1 microgram per deciliter $(\mu \mathrm{g} / \mathrm{dL})$, and all children whose blood lead levels are below this level of detection are assigned this minimum value. Blood lead levels are stored in the NC database as integer values only.
} 
properties. ${ }^{18}$

Table 1 provides summary statistics for all parcels in the county as well as our main estimation sample of LeadSafe applicants by those remediated and those labeled "safe from lead" following an inspection. The average parcel in Charlotte-Mecklenburg has a considerably higher sales price; more bathrooms, living area, and lot size; shorter distance to the CBD; and lower BLL tests. The fact that homes with high lead risk are located in poorer, older neighborhoods is consistent with both the presence of lead in homes built before 1978 as well as the sorting of homebuyers to more affordable homes in neighborhoods with higher environmental risk. Since outcomes in this table reflect both pre and post remediation, these summary statistics simply provide a sense of the scale of home prices, renovations, the likelihood of property sale and lead exposure risk for our sample of LeadSafe applicants. Our treatment and control groups are similar in terms of parcel and neighborhood attributes.

Since one may be concerned that treatment parcels are concentrated in certain neighborhoods while control parcels are in different neighborhoods, and this may be symptomatic of different neighborhood unobservables, we examine the spatial distribution of treatment and control parcels. Figure 2 provides the distribution of distances between parcels for three groups: 1) lead-remediated parcels to other lead-remediated parcels; 2) lead-remediated to non-lead-remediated parcels and 3) all parcels to all other parcels. From this figure, we see that lead-remediated and non-remediated parcels are substantially more spatially concentrated than the general distribution of all parcels. Furthermore, the joint spatial distribution of lead-remediated and non-remediated parcels is almost identical to that of the spatial distribution of lead-remediated parcels, indicating that our treatment and control parcels are spatially concentrated in the same neighborhoods.

\footnotetext{
${ }^{18}$ When we include BLL values as control variables in later regressions, we set missing values to zero for parcels without BLL tests and include a dummy for missing BLL test.
} 


\section{Empirical Framework}

Linking LeadSafe administrative data with county parcel records, we empirically estimate the impact of lead exposure risk on neighborhoods through its capitalization in housing prices. Given the well-known detrimental effects of lead on childhood development, homebuyers will pay substantial premiums for remediated properties or newer neighborhoods to avoid a high (or uncertain) risk of exposure within older properties. To estimate the impact of lead exposure risk on property values, we need a measure of exposure that entails salient information to a homebuyer such as a lead-paint remediation event or the disclosure of information about blood test results indicating high levels of exposure.

Our analysis focuses on substantial changes in information about lead exposure risk for families in older homes following remediation from LeadSafe Charlotte. In a supplementary analysis, we incorporate blood lead level (BLL) test values at a home prior to its sale as a measure of residential lead exposure risk in a hedonic housing price model and report these estimates in the Appendix. ${ }^{19}$ We do not focus on these estimates since measuring the presence of residential exposure using blood test results is problematic for several reasons. First, childhood blood lead levels can reflect exposure through a number of different environments and is, at best, a noisy measure of own-household exposure. Second, as discussed by Aizer et al. (2015) and Billings and Schnepel (2015), there is a great deal of measurement error in testing exposure with blood tests. Both of these factors will attenuate the relationship between this proxy for exposure and property values toward zero. Furthermore, bias can arise through selection on who is tested for lead exposure since the testing decision likely relates to the structural or neighborhood attributes of a home, both observed and unobserved. Finally, lead disclosure laws only require disclosure of known lead inspections or sources of lead in the home and do not require the disclosure of historical blood lead test results.

Our main results include a series of models based on a difference-in-difference

\footnotetext{
${ }^{19}$ We provide standard hedonic housing prices estimates of the relationship between average BLL test values and home prices in Appendix Table A1. Results show a negative relationship between BLL and home prices that becomes smaller and less precise once we control for neighborhood attributes and prior home renovations.
} 
estimator using all properties with applications to LeadSafe Charlotte between the program's inception in 1998 through 2013. Our main estimation equation is given by:

$$
\begin{aligned}
\ln \left(P_{i j t}\right) & =\alpha+\beta_{1} \text { LeadRemediated }_{i} * \text { Post }_{i t}+\beta_{2} \text { LeadRemediated }_{i} \\
& +\beta_{3} \text { Post }_{i t}+\beta_{4} \text { LeadSafeYear }_{t}+\beta_{5} X_{i t}+\delta_{t}+\gamma_{j}+\varepsilon_{i j t}
\end{aligned}
$$

where $P_{i j t}$ is the transacted sales price for a single-family home $i$ in neighborhood $j$ at time $t ; X_{i t}$ includes a wide range of structural attributes given in Table 1. We also include an indicator variable for the year in which the property was inspected by LeadSafe (LeadSafeYear ${ }_{i}$ ); year-by-quarter-of-sale fixed effects $\left(\delta_{t}\right)$; and, in most models, Census Block Group (CBG) fixed effects $\left(\gamma_{j}\right)$. LeadRemediated $_{i}$ indicates whether parcel $i$ is ever remediated by LeadSafe Charlotte between 1998 and 2014; Post $t_{i t}$ indicates whether the transacted sale follows the date of lead inspection for the applicant parcel. The interaction of LeadRemediated $_{i} *$ Post $_{i t}$ represents our difference-in-difference estimator and $\beta_{1}$ is the marginal increase in housing prices following lead remediation. Since lead paint hazards and applicant properties are heavily concentrated in older residential neighborhoods, standard errors are clustered at the Census Block Group (CBG) level. ${ }^{20}$

For a difference-in-difference estimator to be valid it must satisfy the parallel trend assumption, which we present graphically in Figure 3. Each point in Figure 3 represents the average logged home price by years relative to the lead inspection date with its shape indicating whether the observation is part of the treatment or control group. The linear trends are estimated separately for positive and negative years relative to inspection date and demonstrate that both types of parcels had similar upward trends prior to inspection.

The parallel trend assumption in the prior period appears valid, and Figure 3 depicts an upward shift in home prices after lead remediation and no upward shift for the control properties. One may expect that our control group would also see price increases following an inspection finding the property "safe from lead". Figure 3 does not depict significant benefits from such inspection-revealed

\footnotetext{
${ }^{20}$ Our sample incorporates 101 CBGs that contain at least one LeadSafe applicant.
} 
exposure information for our control group. These smaller effects may be due to several factors. First, information from historical inspections revealing no immediate risk becomes salient only after a home is under contract. Even with an inspection report, buyers interested in these control properties may expect future remediation costs in the case that areas where lead paint has been sealed deteriorate over time. As discussed, information during remediation is also likely more salient to potential homebuyers since the process is highly visible to the neighborhood.

Given the similarities in property attributes in Table 1, we formally test if our remediated and non-remediated groups are similar on observable attributes in Table 2. Column one indicates that in models without CBG fixed effects, property attributes are not balanced on observables. However, after including neighborhood (CBG) fixed effects in Column 2, our F-test indicates that we cannot reject the null hypothesis that these property attributes jointly explain remediation among the applicant properties. The only individual coefficient that is statistically significant in predicting remediation is the age of the property, but the magnitude of the estimated effect is small-a 10 year increase in the age of home is associated with an increase of 3 percentage points in the probability of remediation. Within narrowly defined neighborhoods, our treatment and control groups are observationally very similar. Therefore, to strengthen our results, we include CBG fixed effects in our preferred specifications.

\section{Results}

Our primary estimates of the effect of lead paint hazard remediation on property values are given in Table 3. We find that remediation is associated with an increase in property values of $25 \%$ from the difference-in-difference specification (Eq. (1)) including CBG fixed effects. Results are similar without neighborhood fixed effects in Column 1 and when adding school fixed effects in Column 3 of Table 3. Given the average transaction price in our sample is $\$ 80,969$, our estimated effect from remediation translates to a nominal increase of $\$ 20,323$, which represents a substantial return, considering the average cost of remediation is $\$ 7,291$. 
To test whether estimated benefits are driven by the value of property improvements during the lead remediation process, we present estimates from a model which interacts the cost of lead remediation with our post-remediation indicator in Column 4 of Table 3. We find that the actual cost of remediation is not driving our estimated benefits from remediation. This result suggests that benefits are primarily driven by the long-term reduction in exposure risk from remediation. We also explore if our results are concentrated in certain types of neighborhoods in Columns 5 and 6 of Table 3 and find impacts to be similar in magnitude for neighborhoods with a larger share of homes that have lead (based on child lead testing) or older homes.

We test the robustness of results to a repeat sales model as well as some of alternative difference-in-difference specifications in Table 4. Interpretation of our repeat sales model is limited given the few LeadSafe applicants that are sold multiple times within our time period of analysis. We have even fewer repeat sales of our treatment and control properties both before and after remediation. However, despite the small number of observations, estimates from these repeat sales specifications are consistent (albeit less precise) with our primary results reported in Table 3. We also present estimates from a specification that use lead remediation completion date (rather than inspection date) to define the Post $_{i t}$ indicator in Eq. (1) and a model which includes neighborhood-specific time trends. Estimates from these specifications presented in Columns 3 and 4 of Table 4 are also very similar to our primary estimates in Table 3.

We further test the validity of our identification assumptions using three types of falsification tests presented in Table 5. To alleviate concerns that differential trends between treatment and control properties affect our results, the first column in Table 5 implements a model where we change the inspection date to be three years earlier and drop sales after actual lead remediation. Results are small in magnitude and insignificant. To alleviate any concerns that our estimated effects are driven by differential characteristics across our treatment and control groups, the second column in Table 5 uses lead remediated parcels to estimate a first stage model that predicts the likelihood that an applicant parcel is remediated and applies these coefficients to the universe of parcels excluding LeadSafe applicants to create a pool of 1,410 pseudo-applicant sales transactions. We use the top $70 \%$ (the same fraction as the original treatment 
group) of pseudo applicants to create a pseudo treatment group and estimate our difference-in-difference estimator. Again, we find small and insignificant results. Finally, to alleviate any concerns that differential neighborhood characteristics or differential trends across areas with more treatment properties (such as localized gentrification) influence our estimates, our final falsification test in Column 3 of Table 5 estimates pseudo-treatment effects for a sample which includes the nearest neighbor parcels of our estimation group. These pseudo-treatment and pseudo-control applicants should experience identical neighborhood attributes and neighborhood trends as our main sample and, once again, we find small and insignificant effects on property values. These results also indicate that any spillover effects from remediation to neighbor properties are small and not statistically significant.

To explore the dynamics of sorting to and away from lead-remediated homes, we evaluate whether remediation affects residential mobility and other outcomes in Table 6. Because we no longer rely on having a property sales transaction, the models in Table 6 are based on a balanced panel of our sample parcels from 19952014. We implement two sets of models with the top panel providing pooled results and the bottom panel including parcel-level fixed effects (which is feasible now that we have multiple observations for each parcel). Results are consistent across both models and we refer to the bottom model for interpretation.

The first outcome we examine in Column 1 of Table 6 is whether a property was more or less likely to be sold following remediation compared with the control group. Since we do not observe residential relocations for families located at LeadSafe applicant parcels, we have to rely on the sale of a home as an indicator of moving. Of course, home sale is not a perfect measure for residential relocation, but in most cases, an arm's-length transaction of a home indicates new residents. We interpret the decrease in the probability of a sale in a remediated property of 3.5 percentage points (Column 1 of Table 6 ) as evidence that remediation substantially reduces residential turnover. The magnitude of the effect of remediation on residential turnover is very large and represents nearly a $70 \%$ decrease from the average probability of a sale of $5 \%$. In essence, lead remediation is leading homebuyers to have longer tenures at a residence. This result indicates that either existing residents are more willing to stay in a neighborhood or families buying lead-remediated properties are the type of 
households that stay longer in a home. Both scenarios are consistent with a story of less neighborhood turnover and greater housing security by residents, which could lead to long-term benefits for a population facing high rates of housing insecurity and residential mobility. Since our measure of residential movement is not ideal, we also estimate the effects of remediation on residential mobility using a completely different measure of residence based on BLL test addresses at ages one or two and the home addresses at the start of public school for all public school children during our study period. Upon linking these datasets to our applicant properties, Appendix Table B2 shows that remediation decreases residential mobility by a similar magnitude and suggests that those who do move are less likely to relocate to older neighborhoods and neighborhoods with a higher portion of homes that need lead remediation. ${ }^{21}$

We also estimate the effect of remediation on the annual dollars spent on renovations (not including lead remediation based renovations) in Column 2 of Table 6. Results indicate a small effect of lead remediation on renovations of about \$246 which is marginally significant at a $90 \%$ confidence level. Given that we average 9.8 years of renovation costs after remediation, this coefficient translates to about $\$ 2,410$ or $12 \%$ of our total effect on housing prices. This result is consistent with a story of higher property maintenance following remediation, but the effect is small enough that is does not influence our main conclusions regarding the net benefits of lead remediation.

Using the same panel design described for the residential turnover outcome, we also test whether children are more or less likely to be tested for lead exposure after lead remediation. For the specification reported in Column 3 in Table 6, we create a dependent variable that is an indicator as to whether we observe a child at the parcel address in the blood lead surveillance data in each year. We do not find any significant effects of remediation on the probability of testing. Column 4 measures the effect of remediation on the result of the blood lead test for those parcel-year observations in which we observe a blood lead test level. We find a small negative but insignificant effect of remediation on blood lead levels conditional on testing in Column 4 of Table 6.

The lack of a relationship between lead testing and lead remediation may simply reflect the fact that individuals may respond in two opposing ways to knowing

\footnotetext{
${ }^{21}$ These results are described in more detail in Appendix B.
} 
that lead was removed from a home. If parents know a home was remediated, they may be more aware of the potential health risk and may be more likely to have their children tested. On the other hand, remediation reduces the risk of exposure and therefore limits the need for lead testing. The noisy and small detected relationship between blood lead levels and remediation is also influenced by these factors as well as inaccuracies inherent in the testing process. As discussed by Aizer et al. (2015), the measurement error in BLL testing attenuates estimates toward zero so we are likely underestimating the effects of lead remediation on BLL values.

\section{Conclusions}

The large net benefits of remediation are interesting since an informed homebuyer may only increase an initial offer for a remediated property by the estimated cost of remediation. We believe that several factors contribute to the high return on remediation investment. First, families may be willing to pay a premium to know for certain that an old home has been remediated. Even if prior inspection reports indicate a property is "safe from lead", a degree of uncertainty as to future exposure risk within the residence may remain a concern. The risk of exposure (and the damaging effects of lead) may become more apparent to both buyers and sellers following a remediation event given the high profile of lead paint hazard remediation. Previous research documents a larger decline in sales price than the capitalized value of insurance premiums for properties located within a flood zone and risk premiums differing substantially before and after major storms (Bin and Landry, 2013; MacDonald et al., 1987). Therefore, most of the benefits from remediation may result from the removal of uncertainty in both the cost of remediation as well as the risk of lead exposure.

The negative effects of lead exposure on a number of educational and behavioral outcomes is well established in the literature, but less is known about how lead contributes to neighborhoods or housing values. We show that lead remediation increases property values by $25 \%$ and therefore represents a large net benefit for public investment in lead remediation programs-every dollar invested in lead remediation returns three dollars in capitalized benefits to home owners. Our results suggest that lead remediation programs, such as HUD's Healthy Homes 
and Lead Hazard Control Program, which provides grants to LeadSafe Charlotte and other similar organizations, can help address the lasting negative effects of growing up in disadvantaged neighborhoods with high concentrations of environmental toxins. Future assessments of these programs should include the potential benefits to low-income housing values in addition to improvements in childhood health and development from reductions in exposure.

\section{References}

Aizer, Anna, Currie, Janet, Simon, Peter and Vivier, Patrick. (2015), Inequality in Lead Exposure and the Black-White Test Score Gap, Technical report, Working Paper, September 2015.

ATSDR. (1988), The Nature and Extent of Lead Poisoning in Children in the United States: A Report to Congress, Technical report, Agency for Toxic Substances and Disease Registry - Center for Disease Control.

Bae, Hyunhoe. (2012). 'Reducing Environmental Risks By Information Disclosure: Evidence in Residential Lead Paint Disclosure Rule', fournal of Policy Analysis and Management 31(2), 404-431.

Banzhaf, H Spencer and Walsh, Randall P. (2008). 'Do People Vote with their Feet? An Empirical Test of Tiebout's Mechanism', American Economic Review pp. 843-863.

Billings, Stephen B and Schnepel, Kevin T. (2015). 'Life Unleaded: Effects of Early Interventions for Children Exposed to Lead', LCC Working Paper Series 2015-18.

Bin, Okmyung and Landry, Craig E. (2013). 'Changes in implicit flood risk premiums: Empirical evidence from the housing market', fournal of Environmental Economics and Management 65(3), 361-376.

Brown, Mary Jean, McLaine, Pat, Dixon, Sherry and Simon, Peter. (2006). 'A randomized, community-based trial of home visiting to reduce blood lead levels in children', Pediatrics 117(1), 147-153. 
Chay, Kenneth Y and Greenstone, Michael. (2005). 'Does Air Quality Matter? Evidence from the Housing Market', fournal of Political Economy 113(2), 376-424.

Chetty, Raj and Hendren, Nathaniel. (2015), The Impacts of Neighborhoods on Intergenerational Mobility: Childhood Exposure Effects and County-Level Estimates, Technical report, Working Paper, May 2015.

Chetty, Raj, Hendren, Nathaniel and Katz, Lawrence F. (2015), The Effects of Exposure to Better Neighborhoods on Children: New Evidence from the Moving to Opportunity Experiment, Technical Report 21156, National Bureau of Economic Research.

Chetty, Raj, Hendren, Nathaniel, Kline, Patrick and Saez, Emmanuel. (2014), Where is the Land of Opportunity? The Geography of Intergenerational Mobility in the United States, Working Paper 19843, National Bureau of Economic Research.

Currie, Janet, Davis, Lucas, Greenstone, Michael and Walker, Reed. (2015). 'Environmental Health Risks and Housing Values: Evidence from 1,600 Toxic Plant Openings and Closings', American Economic Review 105(2), 678709.

Davis, Lucas W. (2004). 'The effect of health risk on housing values: Evidence from a cancer cluster', American Economic Review pp. 1693-1704.

EPA, U.S. (2013), Integrated Science Assessment for Lead (Final Report), Technical report, U.S. Environmental Protection Agency, Washington, DC, EPA/600/R-10/075F.

Gamper-Rabindran, Shanti and Timmins, Christopher. (2013). 'Does Cleanup of Hazardous Waste Sites Raise Housing Calues? Evidence of Spatially Localized Benefits', fournal of Environmental Economics and Management 65(3), 345-360.

Gazze, Ludovica. (2015), The Price of a Safe Home: Lead Abatement Mandates and the Housing Market, Working paper, MIT. 
Greenstone, Michael and Gallagher, Justin. (2008). 'Does Hazardous Waste Matter? Evidence from the Housing Market and the Superfund Program', The Quarterly fournal of Economics pp. 951-1003.

Jacobs, David E, Clickner, Robert P, Zhou, Joey Y, Viet, Susan M, Marker, David A, Rogers, John W, Zeldin, Darryl C, Broene, Pamela and Friedman, Warren. (2002). 'The prevalence of lead-based paint hazards in US housing.', Environmental Health Perspectives 110(10), A599.

Kahn, Matthew E. (2000). 'Smog Reduction's Impact on California County Growth', fournal of Regional Science 40(3), 565-582.

Lanphear, Bruce P, Howard, Cynthia, Eberly, Shirley, Auinger, Peggy, Kolassa, John, Weitzman, Michael, Schaffer, Stanley J and Alexander, Keith. (1999). 'Primary prevention of childhood lead exposure: a randomized trial of dust control', Pediatrics 103(4), 772-777.

Leggett, Christopher G and Bockstael, Nancy E. (2000). 'Evidence of the effects of water quality on residential land prices', Fournal of Environmental Economics and Management 39(2), 121-144.

Lueck, Thomas. (1991). 'The Pervasive Problem of Lead Paint', New York Times April 7th.

MacDonald, Don N, Murdoch, James C and White, Harry L. (1987). 'Uncertain hazards, insurance, and consumer choice: evidence from housing markets', Land Economics pp. 361-371.

Mastromonaco, Ralph. (2015). 'Do Environmental Right-To-Know Laws Affect Markets? Capitalization of Information in the Toxic Release Inventory', fournal of Environmental Economics and Management 71, 54-70.

Miranda, Marie Lynn, Kim, Dohyeong, Galeano, M. Alicia Overstreet, Paul, Christopher J., Hull, Andrew P. and Morgan, S. Philip. (2007). 'The Relationship between Early Childhood Blood Lead Levels and Performance on End-of-Grade Tests', Environmental Health Perspectives 115(8), 12421247. 
Sanders, Nicholas J. (2012), Toxic Assets: How the Housing Market Responds to Environmental Information Shocks, Working paper, College of William and Mary Department of Economics.

Zhang, Nanhua, Baker, Harolyn W, Tufts, Margaret, Raymond, Randall E, Salihu, Hamisu and Elliott, Michael R. (2013). 'Early childhood lead exposure and academic achievement: evidence from Detroit public schools, 2008-2010', American fournal of Public Health 103(3), e72-e77. 


\section{Figures and Tables}

Figure 1: LeadSafe Inspections by Year

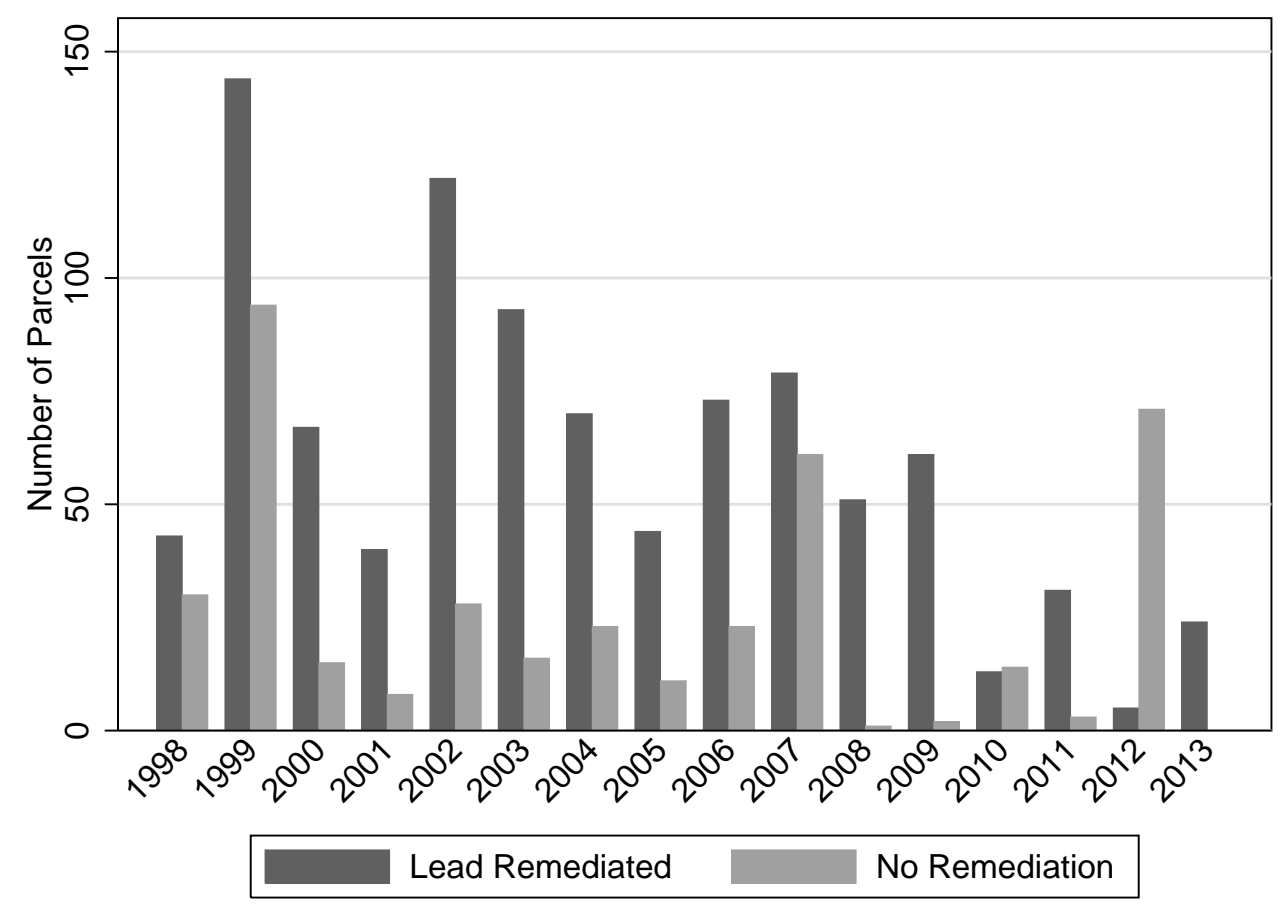

This figure provides the distribution of LeadSafe applicants by inspection date. 
Figure 2: Spatial Distribution of LeadSafe Parcels

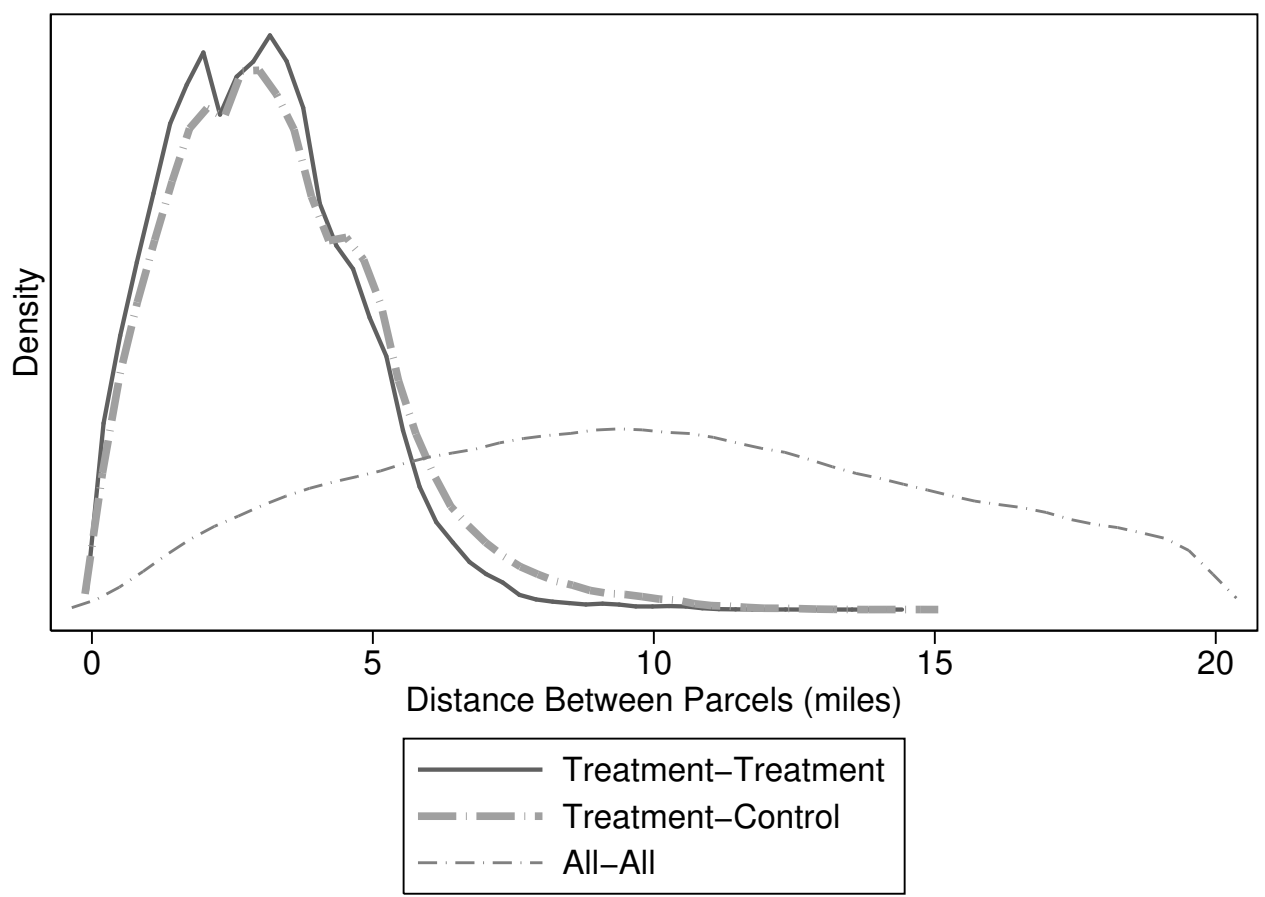

These three distributions above are based on kernel density estimators for all pairwise combinations of treatment parcels to treatment parcels; treatment parcels to control parcels; and a random sample $(\mathrm{N}=500)$ of all parcels to all parcels. 
Figure 3: Difference-in-Difference Figure

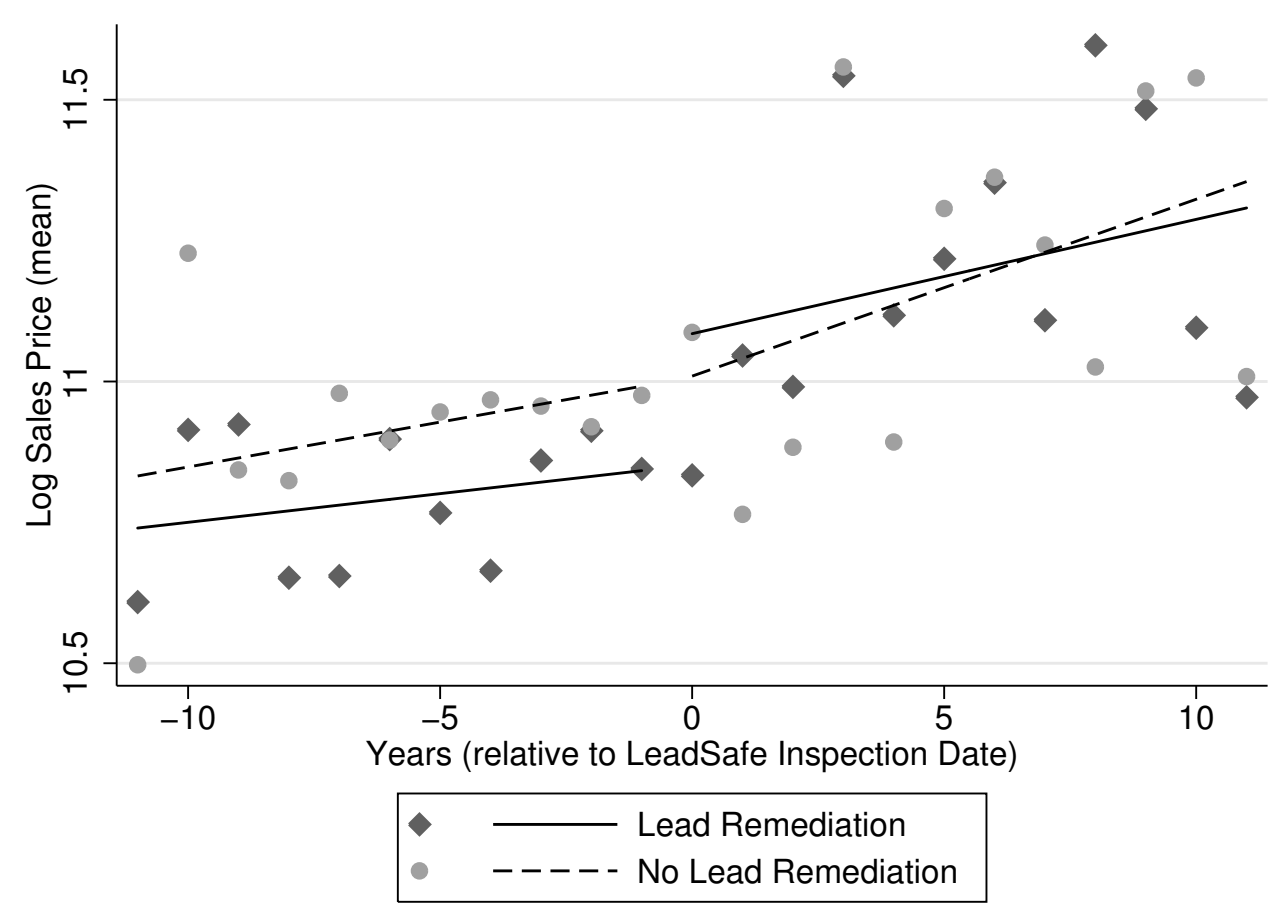

This figure plots the relationship between our dependent variable, $\ln ($ Sales Price), and years relative to LeadSafe inspection for our estimation sample of 1359 parcels. We split results by whether or not lead paint inspection required follow-up remediation. 
Table 1: Descriptive Statistics

\begin{tabular}{|c|c|c|c|}
\hline & All Parcels & $\begin{array}{l}\text { Applicant } \\
\text { Remediated } \\
\text { Treatment }\end{array}$ & $\begin{array}{c}\text { Applicant } \\
\text { Not Remediated } \\
\text { Control }\end{array}$ \\
\hline \multicolumn{4}{|l|}{ Outcomes } \\
\hline Sales price $(\$)$ & $\begin{array}{c}195.426 \\
(148.819)\end{array}$ & $\begin{array}{c}78.735 \\
(90.149)\end{array}$ & $\begin{array}{c}86.332 \\
(91.176)\end{array}$ \\
\hline Renovation Costs (\$) Last 5 years & $\begin{array}{c}1.842 \\
(42.253)\end{array}$ & $\begin{array}{c}1.365 \\
(8.222)\end{array}$ & $\begin{array}{c}1.512 \\
(5.692)\end{array}$ \\
\hline Property Sold & $\begin{array}{c}0.72 \\
(0.45)\end{array}$ & $\begin{array}{c}0.55 \\
(0.50)\end{array}$ & $\begin{array}{c}0.47 \\
(0.50)\end{array}$ \\
\hline Average BLL in home & $\begin{array}{c}3.52 \\
(2.60)\end{array}$ & $\begin{array}{c}5.33 \\
(4.53)\end{array}$ & $\begin{array}{c}4.51 \\
(2.65)\end{array}$ \\
\hline \multicolumn{4}{|l|}{ Parcel Attributes } \\
\hline Lot Size (Acres) & $\begin{array}{c}0.57 \\
(3.46)\end{array}$ & $\begin{array}{c}0.23 \\
(0.10)\end{array}$ & $\begin{array}{c}0.26 \\
(0.19)\end{array}$ \\
\hline Bathrooms & $\begin{array}{c}2.08 \\
(0.79)\end{array}$ & $\begin{array}{c}1.13 \\
(0.38)\end{array}$ & $\begin{array}{c}1.23 \\
(0.50)\end{array}$ \\
\hline Living Area (Sqft 00s) & $\begin{array}{c}20.13 \\
(11.03)\end{array}$ & $\begin{array}{l}11.21 \\
(3.29)\end{array}$ & $\begin{array}{l}11.82 \\
(3.40)\end{array}$ \\
\hline Fireplace & $\begin{array}{c}0.80 \\
(0.40)\end{array}$ & $\begin{array}{c}0.43 \\
(0.50)\end{array}$ & $\begin{array}{c}0.34 \\
(0.48)\end{array}$ \\
\hline Age of Building (years) & $\begin{array}{c}26.74 \\
(26.44)\end{array}$ & $\begin{array}{c}62.74 \\
(15.03)\end{array}$ & $\begin{array}{c}57.55 \\
(16.35)\end{array}$ \\
\hline Built pre 1978 & $\begin{array}{c}0.41 \\
(0.49)\end{array}$ & $\begin{array}{l}1.00 \\
(0.00)\end{array}$ & $\begin{array}{c}1.00 \\
(0.00)\end{array}$ \\
\hline Distance to CBD (miles) & $\begin{array}{c}8.22 \\
(3.91)\end{array}$ & $\begin{array}{c}2.37 \\
(0.87)\end{array}$ & $\begin{array}{c}2.76 \\
(1.31)\end{array}$ \\
\hline Distance to Highway (miles) & $\begin{array}{c}1.98 \\
(1.32)\end{array}$ & $\begin{array}{c}0.81 \\
(0.59)\end{array}$ & $\begin{array}{c}0.86 \\
(0.78)\end{array}$ \\
\hline Neighborhood Attributes & & & \\
\hline Median HH Income (000s) & $\begin{array}{l}61.80 \\
(26.30)\end{array}$ & $\begin{array}{l}26.61 \\
(6.30)\end{array}$ & $\begin{array}{l}28.74 \\
(8.97)\end{array}$ \\
\hline Percent Black Residents & $\begin{array}{c}0.23 \\
(0.25)\end{array}$ & $\begin{array}{c}0.81 \\
(0.18)\end{array}$ & $\begin{array}{c}0.78 \\
(0.21)\end{array}$ \\
\hline Percent White Residents & $\begin{array}{c}0.70 \\
(0.27)\end{array}$ & $\begin{array}{c}0.13 \\
(0.17)\end{array}$ & $\begin{array}{c}0.15 \\
(0.20)\end{array}$ \\
\hline Percent Homes pre 1978 & $\begin{array}{c}0.37 \\
(0.32)\end{array}$ & $\begin{array}{c}0.85 \\
(0.15)\end{array}$ & $\begin{array}{c}0.80 \\
(0.20)\end{array}$ \\
\hline Observations & 204,256 & 960 & 400 \\
\hline
\end{tabular}


Table 2: Balancing Test

\begin{tabular}{|c|c|c|}
\hline & $\begin{array}{c}(1) \\
\text { Remediated } \\
\text { Treatment }\end{array}$ & $\begin{array}{c}(2) \\
\text { Remediated } \\
\text { Treatment }\end{array}$ \\
\hline Renovation Costs ( $\$ 000)$ Last 5 years & $\begin{array}{c}1.329 \\
(2.705)\end{array}$ & $\begin{array}{c}0.143 \\
(2.704)\end{array}$ \\
\hline Lot Size (Acres) & $\begin{array}{l}-0.155 \\
(0.093)\end{array}$ & $\begin{array}{c}-0.107 \\
(0.115)\end{array}$ \\
\hline Bathrooms & $\begin{array}{c}0.016 \\
(0.038)\end{array}$ & $\begin{array}{c}-0.013 \\
(0.041)\end{array}$ \\
\hline Living Area (Sqft - 00s) & $\begin{array}{r}-0.009^{*} \\
(0.005)\end{array}$ & $\begin{array}{l}-0.007 \\
(0.005)\end{array}$ \\
\hline Fireplace & $\begin{array}{r}0.045^{*} \\
(0.026)\end{array}$ & $\begin{array}{l}0.007 \\
(0.032)\end{array}$ \\
\hline Age of Building & $\begin{array}{l}0.003^{* * *} \\
(0.001)\end{array}$ & $\begin{array}{l}0.003^{* *} \\
(0.001)\end{array}$ \\
\hline Distance to CBD (miles) & $\begin{array}{c}-0.000 \\
(0.019)\end{array}$ & $\begin{array}{c}0.055 \\
(0.101)\end{array}$ \\
\hline Distance to Highway (miles) & $\begin{array}{l}0.053^{* *} \\
(0.023)\end{array}$ & $\begin{array}{c}0.120 \\
(0.099)\end{array}$ \\
\hline Average BLL in home & $\begin{array}{l}0.009 \\
(0.006)\end{array}$ & $\begin{array}{c}0.008 \\
(0.007)\end{array}$ \\
\hline No prior BLL Tests & $\begin{array}{c}0.064 \\
(0.045)\end{array}$ & $\begin{array}{c}0.071 \\
(0.049)\end{array}$ \\
\hline Median HH Income (000s) & $\begin{array}{l}-0.005^{* *} \\
(0.002)\end{array}$ & \\
\hline Percent Black Residents & $\begin{array}{r}0.412^{*} \\
(0.223)\end{array}$ & \\
\hline Percent White Residents & $\begin{array}{r}0.472^{*} \\
(0.254)\end{array}$ & \\
\hline $\begin{array}{l}\text { F-Stat (p-value) } \\
\text { CBG Fixed Effects }\end{array}$ & 0.000 & $\begin{array}{c}0.225 \\
\text { Yes }\end{array}$ \\
\hline Observations & 1,360 & 1,360 \\
\hline
\end{tabular}

${ }^{*} \mathrm{p}<0.1,{ }^{* *} \mathrm{p}<0.05,{ }^{* * *} \mathrm{p}<0.01$. Standard errors robust to arbitrary correlation within CBG. Dependent variable is a dummy for LeadSafe Remediated. We include, but do not report, coefficients for a series of dummies for applicant year. 
Table 3: Effects of LeadSafe Remediation on Housing Prices

\begin{tabular}{|c|c|c|c|c|c|c|}
\hline Dep Var: $\ln ($ Sales Price $)$ & (1) & $(2)$ & (3) & (4) & $\begin{array}{l}\text { (5) } \\
\text { Only } \\
\text { Neighs } \\
\text { High } \\
\text { Lead }\end{array}$ & $\begin{array}{l}\text { (6) } \\
\text { Only } \\
\text { Neighs } \\
\text { Older } \\
\text { Homes }\end{array}$ \\
\hline LeadSafe Remediation ${ }^{*}$ Post & $\begin{array}{c}0.245^{* *} \\
(0.105)\end{array}$ & $\begin{array}{l}0.251^{* *} \\
(0.112)\end{array}$ & $\begin{array}{l}0.256^{* *} \\
(0.114)\end{array}$ & $\begin{array}{c}0.234^{*} \\
(0.136)\end{array}$ & $\begin{array}{c}0.194^{*} \\
(0.102)\end{array}$ & $\begin{array}{c}0.202^{*} \\
(0.102)\end{array}$ \\
\hline LeadSafe Remediation & $\begin{array}{c}-0.124^{*} \\
(0.071)\end{array}$ & $\begin{array}{c}-0.115 \\
(0.083)\end{array}$ & $\begin{array}{c}-0.113 \\
(0.085)\end{array}$ & $\begin{array}{c}-0.114 \\
(0.083)\end{array}$ & $\begin{array}{c}-0.078 \\
(0.094)\end{array}$ & $\begin{array}{c}-0.001 \\
(0.114)\end{array}$ \\
\hline Post & $\begin{array}{c}-0.011 \\
(0.124)\end{array}$ & $\begin{array}{c}-0.083 \\
(0.125)\end{array}$ & $\begin{array}{c}-0.079 \\
(0.126)\end{array}$ & $\begin{array}{c}-0.082 \\
(0.126)\end{array}$ & $\begin{array}{c}-0.069 \\
(0.101)\end{array}$ & $\begin{array}{c}-0.149 \\
(0.115)\end{array}$ \\
\hline LeadSafe Remediation ${ }^{*}$ Post $^{*}$ Amount(\$) & & & & $\begin{array}{c}0.002 \\
(0.007)\end{array}$ & & \\
\hline Fixed Effects & & $\mathrm{CBG}$ & CBG, Schools & CBG & CBG & $\mathrm{CBG}$ \\
\hline Observations & 1,410 & 1,410 & 1,410 & 1,410 & 709 & 725 \\
\hline \multicolumn{7}{|c|}{$\begin{array}{l}{ }^{*} \mathrm{p}<0.1,{ }^{* *} \mathrm{p}<0.05,{ }^{* *} \mathrm{p}<0.01 \text {. Standard errors robust to arbitrary correlation within the } 101 \mathrm{CBGs} \text { that contain } \\
\text { our applicant parcels. Dependent variable in all models is } \ln (\text { sales price). All models include standard hedonic } \\
\text { controls including polynomials in age and square feet, lot size, baths, fireplace, year and quarter of sales fixed } \\
\text { effects and we limit our sample to single family homes. We define the date to indicate the pre/post period based } \\
\text { on the lead inspection date for either the remediated or non-remediated parcels. In some cases, the specific date } \\
\text { was not given, so we base lead inspection date on annual grant cycle reporting dates as part of the LeadSafe grant } \\
\text { program reporting to Housing and Urban Development (HUD). }\end{array}$} \\
\hline $\begin{array}{l}\text { We report results for separate models } \\
\text { older housing stock (pre 1978). We bi } \\
\text { values of these attributes. LeadSafe } \\
\text { difference coefficient with the amoun } \\
\text { due to the property improvement tha }\end{array}$ & $\begin{array}{l}\text { y neighbor } \\
\text { sect into hi } \\
\text { emediation } \\
\text { spent on le } \\
\text { coincide w }\end{array}$ & $\begin{array}{l}\text { hood attrib } \\
\text { gh/low lea } \\
{ }^{*} \text { Post }{ }^{*} \text { Ams } \\
\text { ead remedi } \\
\text { ith lead re }\end{array}$ & $\begin{array}{l}\text { ates for presence } \\
\text { and older/newe } \\
\text { unt }(\$) \text { provides } \\
\text { tion. This variab } \\
\text { lediation. }\end{array}$ & $\begin{array}{l}\mathrm{f} \text { lead bas } \\
\text { neighborl } \\
\text { interacti } \\
\text { highlight }\end{array}$ & $\begin{array}{l}\mathrm{d} \text { on BLL } \\
\text { oods based } \\
n \text { of our } d \\
\text { if there are }\end{array}$ & $\begin{array}{l}\text { as well as } \\
\text { average } \\
\text { ny effects }\end{array}$ \\
\hline
\end{tabular}

Table 4: Robustness Checks

Effects of LeadSafe Remediation on Housing Prices

(1)

\begin{tabular}{lcccc} 
& Repeat Sales & $\begin{array}{c}\text { Repeat Sales } \\
\text { fust Parcels } \\
\text { Pre \& Post } \\
\text { Inspection }\end{array}$ & $\begin{array}{c}\text { Alternative } \\
\text { Remediation } \\
\text { Date }\end{array}$ & $\begin{array}{c}\text { Neigh } \\
\text { Time } \\
\text { Trends }\end{array}$ \\
\hline LeadSafe Remediation ${ }^{*}$ Post & 0.180 & $0.217^{* *}$ & $0.266^{* *}$ & $0.235^{*}$ \\
LeadSafe Remediation & $(0.136)$ & $(0.096)$ & $(0.112)$ & $(0.125)$ \\
Post & $\mathrm{n} / \mathrm{a}$ & $\mathrm{n} / \mathrm{a}$ & -0.119 & -0.087 \\
& -0.203 & $\mathrm{n} / \mathrm{a}$ & $-0.082)$ & $(0.092)$ \\
Observations & $(0.151)$ & & $(0.127)$ & $(0.135)$ \\
\hline
\end{tabular}

${ }^{*} \mathrm{p}<0.1,{ }^{* *} \mathrm{p}<0.05,{ }^{* * *} \mathrm{p}<0.01$. Standard errors robust to arbitrary correlation within CBG. For repeat sales observations, we remove properties which had a high probability of major renovations by excluding repeat sales with more than $100 \%$ appreciation between sales or sales that occurred less than 2 years apart. Column 3 varies from column one due to the removal of parcels that did not have a transacted sale both before and after lead inspection. Non-repeat sales models include standard hedonic controls including polynomials in age and square feet, lot size, baths, fireplace. All models include quarter-year for each sale as well as applicant year fixed effects. 
Table 5: Falsification (Placebo) Checks Effects of LeadSafe Remediation on Housing Prices

\begin{tabular}{|c|c|c|c|}
\hline & $\begin{array}{c}\text { (1) } \\
\text { False } \\
\text { Leadsafe Date } \\
3 \text { years prior } \\
\text { CBG FEs }\end{array}$ & $\begin{array}{c}\text { (2) } \\
\text { False } \\
\text { Predicted LeadSafe } \\
\text { CBG FEs }\end{array}$ & $\begin{array}{c}(3) \\
\text { False } \\
\text { Neighbor of } \\
\text { Leadsafe } \\
\text { CBG FEs }\end{array}$ \\
\hline LeadSafe Remediation*Post & $\begin{array}{c}-0.008 \\
(0.087)\end{array}$ & $\begin{array}{c}0.008 \\
(0.083)\end{array}$ & $\begin{array}{c}0.035 \\
(0.077)\end{array}$ \\
\hline LeadSafe Remediation & $\begin{array}{c}-0.084 \\
(0.064)\end{array}$ & $\begin{array}{c}-0.029 \\
(0.051)\end{array}$ & $\begin{array}{c}-0.017 \\
(0.067)\end{array}$ \\
\hline Post & $\begin{array}{c}-0.031 \\
(0.106)\end{array}$ & $\begin{array}{c}0.069 \\
(0.085)\end{array}$ & $\begin{array}{c}0.097 \\
(0.088)\end{array}$ \\
\hline Observations & 955 & 1,410 & 2,088 \\
\hline
\end{tabular}

${ }^{*} \mathrm{p}<0.1,{ }^{* *} \mathrm{p}<0.05,{ }^{* * *} \mathrm{p}<0.01$. Standard errors robust to arbitrary correlation within CBG. Dependent variable in all models is $\ln$ (sales price) and all models include CBG fixed effects. All models include standard hedonic controls including polynomials in age and square feet, lot size, baths, fireplace, year and quarter of sales fixed effects and we limit our sample to single family homes.

We provide three types of falsifications. The first falsification test is based on assuming LeadSafe inspections occur three years prior and we drop post LeadSafe observations. The second falsification is based on predicting LeadSafe remediation based on property attributes, dropping LeadSafe applicants and using predicated values to determine pool of pseudo applicants. We use the top 30\% (same number as original treatment group) of applicants to create a pseudo treatment group and estimate our difference-in-difference estimator. The third falsification takes the neighboring parcels of LeadSafe applicants and generates psuedo remediation parcels for neighbors of actual LeadSafe remediated homes as well as psuedo non-remediated parcels based on neighbors of applicants without remediation. 
Table 6: Other Outcomes:

Residential Mobility, Housing Renovations, and Blood Lead Tests

\begin{tabular}{|c|c|c|c|c|}
\hline & $\begin{array}{l}(1) \\
\text { Any } \\
\text { Sale }\end{array}$ & $\begin{array}{c}\text { (2) } \\
\text { Renovation Cost }\end{array}$ & $\begin{array}{c}(3) \\
\text { Any } \\
\text { Lead Test }\end{array}$ & $\begin{array}{c}\quad(4) \\
\text { Lead Value }\end{array}$ \\
\hline \multicolumn{5}{|l|}{ CBG and Year FEs } \\
\hline LeadSafe Remediation*Post & $\begin{array}{c}-0.033^{* * *} \\
(0.008)\end{array}$ & $\begin{array}{c}222.617^{*} \\
(118.523)\end{array}$ & $\begin{array}{c}-0.000 \\
(0.007)\end{array}$ & $\begin{array}{c}-0.291 \\
(0.596)\end{array}$ \\
\hline LeadSafe Remediation & $\begin{array}{l}0.017^{* *} \\
(0.007)\end{array}$ & $\begin{array}{c}-209.407^{* * *} \\
(64.272)\end{array}$ & $\begin{array}{c}0.005 \\
(0.008)\end{array}$ & $\begin{array}{c}0.217 \\
(0.504)\end{array}$ \\
\hline Post & $\begin{array}{l}0.013^{* *} \\
(0.006)\end{array}$ & $\begin{array}{c}209.331^{* *} \\
(92.762)\end{array}$ & $\begin{array}{l}-0.027^{* * *} \\
(0.006)\end{array}$ & $\begin{array}{c}-1.269^{* *} \\
(0.528)\end{array}$ \\
\hline \multicolumn{5}{|l|}{$\underline{\text { Parcel and Year FEs }}$} \\
\hline LeadSafe Remediation*Post & $\begin{array}{c}-0.035^{* * *} \\
(0.007)\end{array}$ & $\begin{array}{c}245.975^{*} \\
(126.551)\end{array}$ & $\begin{array}{c}0.003 \\
(0.007)\end{array}$ & $\begin{array}{c}-0.205 \\
(0.926)\end{array}$ \\
\hline Observations & 25,821 & 25,821 & 25,821 & 938 \\
\hline Dep. Var. (mean) & 0.05 & 330.80 & 0.04 & 4.02 \\
\hline
\end{tabular}




\section{Appendix - For Online Publication}

\section{A. Hedonic Estimates of Lead Exposure on Housing Values Using Blood Lead Surveillance Data to Proxy for Parcel-Level Exposure}

As a supplementary exercise to our primary analysis, we estimated a series of hedonic housing price regressions in order to test the relationship between the presence of lead in a home and property values. The standard hedonic model is given by:

$$
\ln \left(P_{i j t}\right)=\alpha+\beta_{1} B L L_{i j t-T}+\beta_{2} X_{i t}+\delta_{t}+\gamma_{j}+\varepsilon_{i j t}
$$

where our dependent variable and control variables are as described in Eq. (1). In this specification, our main variable of interest is $B L L_{i j t-T}$ which indicates the average blood lead level for individuals tested prior to the sale of a parcel. Since poor home maintenance coincides with increased risk of lead exposure, we also incorporate measures of housing renovations to account for the general maintenance level of a home. Since the presence of lead paint is heavily concentrated in older residential neighborhoods, standard errors are clustered at the Census Block Group (CBG) level.

The top part of Table A1 provides estimates of $\beta_{1}$ for a series of models that estimates the marginal effect of a 1 unit increase in mean BLL previously tested at a home. Column 1 provides standard hedonic estimates of a $1.3 \%$ decrease in property values for a 1 unit increase in prior BLL tests for a given property sale. The bottom part of Table A1 estimates a series of dummies for BLL levels of concern as recommended by the Center for Disease Control (CDC). In these models, the excluded category is homes with average BLL less than 2, which indicates no lead exposure. ${ }^{22}$ Column 1 shows larger effects for higher previous lead tests with an average BLL of 10 or more generating a $12 \%$ decrease in home values. Column 2 adds an additional control variable for housing renovations prior to the home's sale and Column 3 adds CBG fixed effects. The inclusion of CBG fixed effects generates a substantial decline in the relationship between lead

\footnotetext{
${ }^{22}$ The lowest possible BLL is 1 and we exclude a few BBL tests of greater than 44 .
} 
tests and property values. These nosier results with CBG fixed effects highlight some issues with using BLL tests as a measure of lead exposure risk. First, BLL tests are not necessarily known to homebuyers because lead disclosure laws only require disclosure of known lead inspections in the home. Second, the general condition of the home impacts BLL tests and home values and thus estimates may capture the effects of both home maintenance and lead exposure risk. The controls for prior renovations as well as neighborhood fixed effects mitigate some of the effects of home maintenance, but we are not able to completely address this concern. Therefore, we focus on our main model that identifies the relationship between exposure and housing prices using large shocks to exposure and information generated by remediation.

Table A1: Relationship Between Blood Lead Test Results and Property Values

\begin{tabular}{|c|c|c|c|c|}
\hline & (1) & $\begin{array}{c}\text { (2) } \\
\text { Control for } \\
\text { Neigh Covars }\end{array}$ & $\begin{array}{c}(3) \\
\text { Control for } \\
\text { Neigh Covars } \\
\text { \& Renovations }\end{array}$ & $\begin{array}{c}(4) \\
\text { Add CBG } \\
\text { Fixed Effects }\end{array}$ \\
\hline Average BLL in home (prior to sale) & $\begin{array}{l}-0.0131^{* * *} \\
(0.0024)\end{array}$ & $\begin{array}{c}-0.0020 \\
(0.0014)\end{array}$ & $\begin{array}{c}-0.0020 \\
(0.0014)\end{array}$ & $\begin{array}{c}-0.0002 \\
(0.0011)\end{array}$ \\
\hline $2 \leqslant B L L \leqslant 4$ & $\begin{array}{l}-0.0683^{* * *} \\
(0.0103)\end{array}$ & 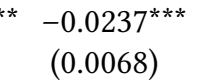 & $\begin{array}{c}-0.0226^{* * *} \\
(0.0068)\end{array}$ & $\begin{array}{c}-0.0127^{* *} \\
(0.0062)\end{array}$ \\
\hline $5 \leqslant B L L \leqslant 9$ & $\begin{array}{l}-0.1212^{* * *} \\
(0.0168)\end{array}$ & 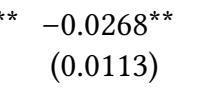 & $\begin{array}{c}-0.0258^{* *} \\
(0.0113)\end{array}$ & $\begin{array}{c}-0.0082 \\
(0.0090)\end{array}$ \\
\hline$B L L \geqslant 10$ & $\begin{array}{l}-0.1190^{* * *} \\
(0.0389)\end{array}$ & $\begin{array}{c}-0.0339 \\
(0.0278)\end{array}$ & $\begin{array}{c}-0.0322 \\
(0.0278)\end{array}$ & $\begin{array}{c}-0.0208 \\
(0.0246)\end{array}$ \\
\hline Observations & 27,768 & 27,768 & 27,768 & 27,768 \\
\hline
\end{tabular}

${ }^{*} \mathrm{p}<0.1,{ }^{* *} \mathrm{p}<0.05,{ }^{* * *} \mathrm{p}<0.01$. Standard errors robust to arbitrary correlation within CBG.

All models include standard hedonic controls including polynomials in age and square feet, lot size, baths, fireplace, year and quarter of sales fixed effects and we limit our sample to single family homes. Dependent variable in all models is $\log$ (sales price). Measures of lead based on average BLL tests prior to any property sale. The lowest possible BLL is 1 and we exclude a few BBL tests of greater than 44 . 


\section{B. Effects of Remediation on Residential Mobility Using Public School and Blood Lead Surveillance Data}

Since our measure of residential movement is not ideal, we also estimate the effects of remediation on residential mobility using a dataset of children in public schools. This dataset, which is described in more detail in Billings and Schnepel (2015), includes all public school children and their residential address during their first year of attending school. We first link individuals to our sample of LeadSafe applicant properties at the time of a first blood lead test (typically between the age of one and two) using blood lead surveillance data and then measure whether the address reported when the individual first enters school (typically between the age of five and six) has changed from the address first reported in the blood lead testing data. Table B2 reports estimated effects of remediation on this indicator of residential mobility. We estimate a significant decrease in the probability of moving between blood lead testing and school entry for those living in LeadSafe remediation properties. These results generate the same conclusions as Table 6 in that individuals in lead remediated properties are less likely to move. ${ }^{23}$ When limiting our sample to only those who move between testing and school entry in Columns 3 and 4, we find patterns of results suggesting that children tied to remediated properties may be less likely to move into older neighborhoods or neighborhoods with a larger share of lead paint homes after lead remediation.

\footnotetext{
${ }^{23}$ The magnitudes of these results are not directly comparable to Table 6 for two reasons. First, these results are looking at any residential moves by the time a child starts school (different time period). Second, school moves are based on a cross-section of applicant parcels and not the panel dataset used in Table 6.
} 
Table B2: Effects on Other Outcomes Residential Mobility using Public School Records

\begin{tabular}{|c|c|c|c|}
\hline & $\begin{array}{c}\text { (1) } \\
\text { Moved by } \\
\text { School Start }\end{array}$ & $\begin{array}{c}(2) \\
\text { Moved to } \\
\text { High Lead } \\
\text { Neigh } \\
\text { movers }\end{array}$ & $\begin{array}{c}(3) \\
\text { Moved to } \\
\text { Older } \\
\text { Neigh } \\
\text { movers }\end{array}$ \\
\hline LeadSafe Remediation*Post & $\begin{array}{l}-0.192^{* * *} \\
(0.067)\end{array}$ & $\begin{array}{c}-0.385 \\
(0.345)\end{array}$ & $\begin{array}{c}-0.300 \\
(0.238)\end{array}$ \\
\hline LeadSafe Remediation & $\begin{array}{c}-0.047 \\
(0.063)\end{array}$ & $\begin{array}{c}0.144 \\
(0.191)\end{array}$ & $\begin{array}{c}0.233^{*} \\
(0.137)\end{array}$ \\
\hline Post & $\begin{array}{c}0.009 \\
(0.063)\end{array}$ & $\begin{array}{c}0.278 \\
(0.334)\end{array}$ & $\begin{array}{c}0.337^{*} \\
(0.190)\end{array}$ \\
\hline Observations & 879 & 179 & 179 \\
\hline Dep. Var. (mean) & 0.76 & 0.36 & 0.28 \\
\hline
\end{tabular}

